\title{
Repensant, reescrivint, refent o aprenent a ensenyar ciències mitjançant l'anglès
}

\author{
Roser Canet i Pladevall \\ IES Montserrat, Barcelona \\ rcanet@xtec.cat
}

Es presenten les reflexions sobre didàctica de les ciències generades a partir de les revisions del material didàctic AICLE (ciències naturals en anglès) per a 1r d'ESO, realizades a la UAB durant les tutories amb la Dra. Cristina Escobar, de Didàctica de la Llengua, i la Dra. Neus Sanmartí, de Didàctica de les Ciències. Els materials han estat experimentats a l'Institut Montserrat amb un grup de 30 alumnes gràcies al Pla Experimental de Llengües Estrangeres concedit pel Departament d'Educació.

Paraules clau: AICLE, didàctica de les ciències, idees prèvies, evidències, argumentació, valors

Choose the correct answers:

All living things:
a) eat to get energy
b) can move
c) can grow
d) die
e) interact with the environment

Figure 1. Example of a multiple-choice question to test students' previous ideas.

\section{Context general}

Els materials dissenyats són de Ciències Naturals en anglès per a $1 r$ d'ESO. S'han experimentat en un grup de 30 alumnes de l'IES Montserrat de Barcelona, un centre que té concedit un PELE pel Departament d'Educació. Els alumnes són majoritàriament catalanoparlants amb el nivell que correspon d'anglès en acabar la primària.

Les discussions com a professores ens han dut a replantejar-nos el contingut científic i alhora proporcionar els ajuts lingüístics per tal d'aconseguir que els alumnes siguin capaços d'expressar les seves pròpies idees en anglès, contrastar-les amb les de la ciència actual i abstreure les que són fonamentals per continuar aprenent.

\section{Idees prèvies}

Abans de començar les unitats didàctiques és important que coneguem les idees que tenen els estudiants sobre el que anem a treballar.

Hem de fugir dels estereotips que solem trobar als llibres de ciències i a la vegada proporcionar recursos lingüístics. Per això no donarem preguntes obertes, sinó més aviat qüestions amb resposta múltiple o bé diagrames en els quals hauran de dibuixar-hi alguna cosa, o bé davant d'un experiment expressat gràficament podem fer una pregunta senzilla. Posteriorment analitzarem les respostes en una altra sessió.

\section{Estructura de la unitat}

Un cop detectats els coneixements previs és molt útil presentar els objectius didàctics de la unitat: és bo que els alumnes sàpiguen què aprendran i, per això, ens són molt recomanables els mapes conceptuals. Davant d'unes preguntes els alumnes aniran elaborant respostes al llarg de la unitat i estaran, així, situats en el procés d'ensenyament- 


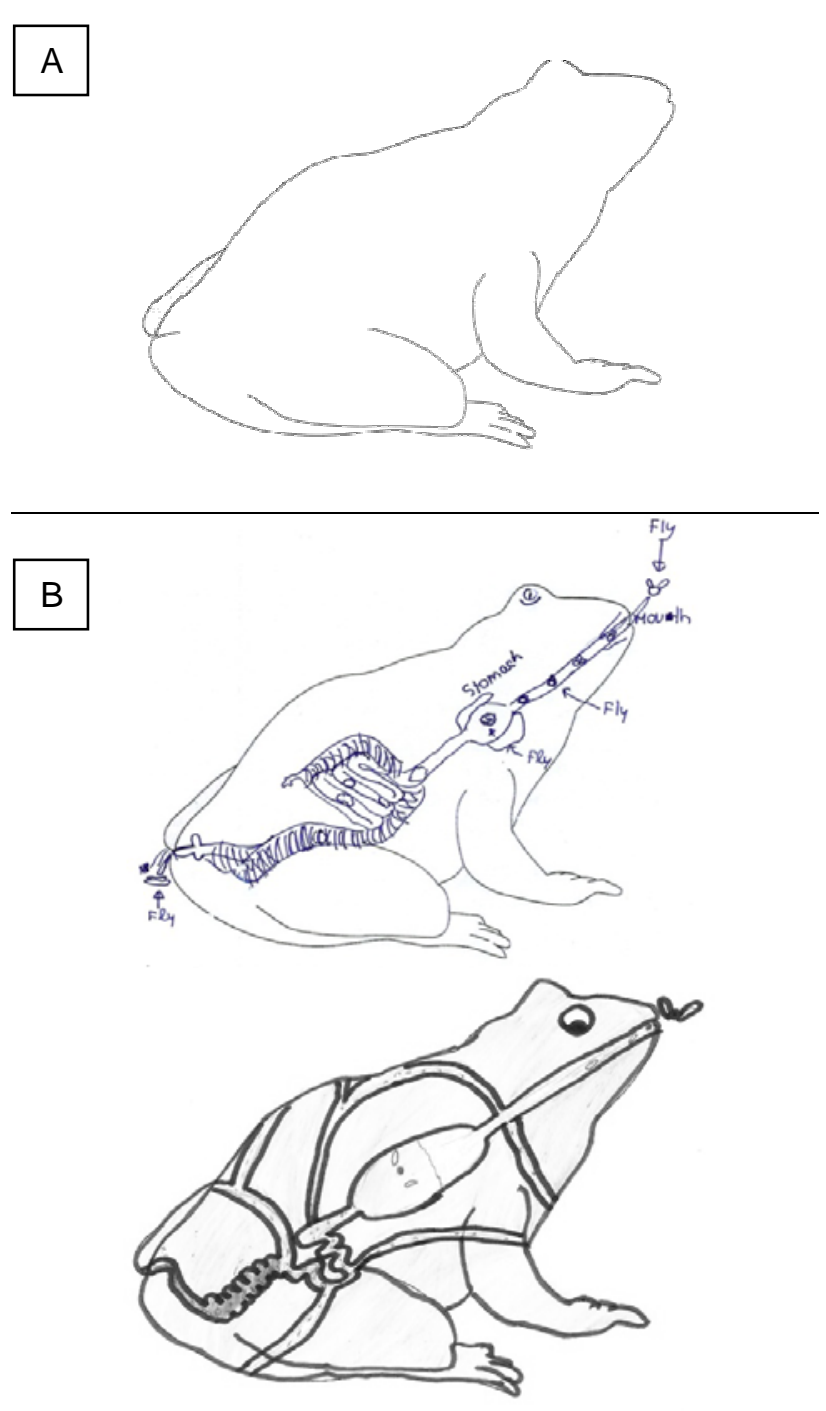

Figure 2. Alternative task to check students' previous ideas about nutrition. A: Empty image of a frog. B: Students' drawings. aprenentatge. Aquí és crucial l'ús de connectors i, per tant, el/la professor/a d'anglès hi té un paper molt important per practicar oralment i per escrit les diferents expressions. Pensem que la coordinació entre el professorat de ciències i d'anglès ha de ser molt estreta.

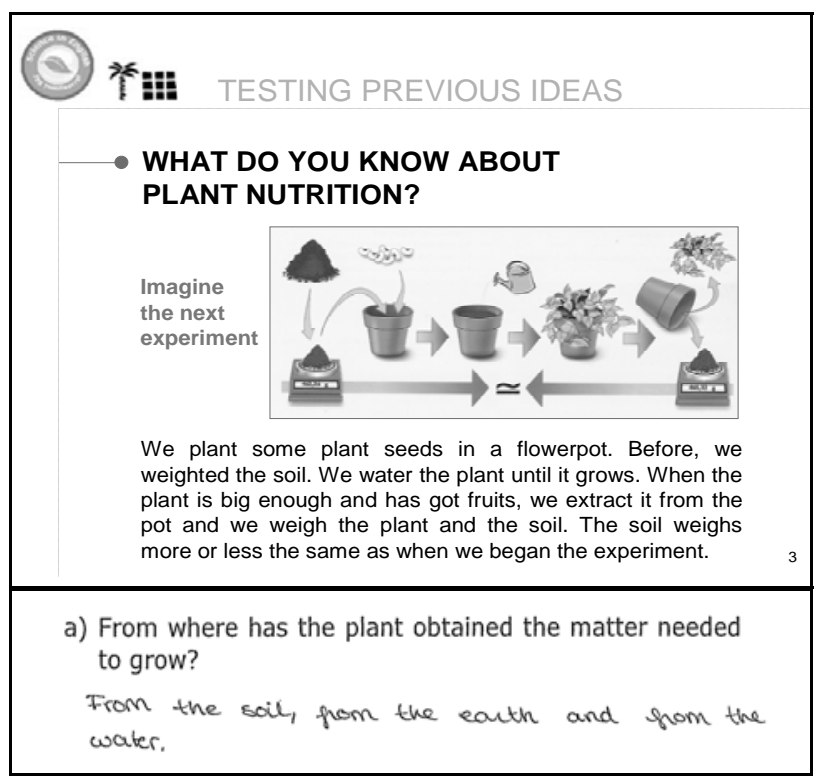

Figure 3. Teaching material on plant nutrition and the example of a student's answer.

\section{Identificar evidències}

En els materials que presentem hem intentat fugir de continguts massa nominatius i mecànics. Per contra, creiem que l'ensenyament és més productiu i efectiu sempre que aprenguem identificant evidències. En l'ensenyament tradicional, havíem fet

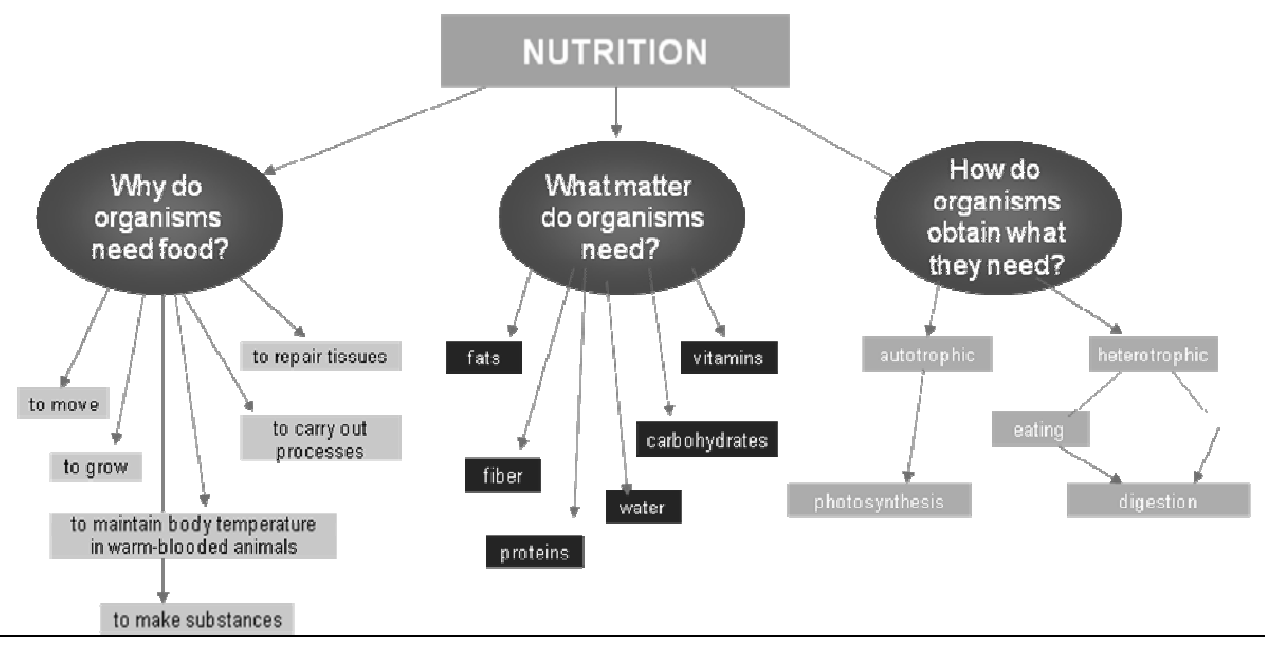

Figure 4. An example of a filled mind map on one of the unit's objectives: Nutrition. 
classe de teoria i després anàvem al laboratori a veure "allò". Ara ho fem a l'inrevés: després d'haver vist cèl-lules al laboratori, d'haver-les dibuixat, d'haver-ne identificat algunes estructures, anirem a l'aula a estudiar la cèl.lula.

Un altre exemple: després d'haver vist euglenes al laboratori i destriat les característiques d'aquest ésser viu, els alumnes veuran la necessitat d'un altre regne, a banda del de les plantes i del dels animals, perquè s'adonaran que aquest organisme no encaixa en cap dels dos regnes anteriors.

\section{Connectar la realitat i l'abstracció}

Voldríem ressaltar que el que fan els/les alumnes a l'aula no ha d'estar deslligat de la seva realitat. A tall d'exemple: estàvem acostumats a explicar les biomolècules que formen part de la matèria viva donant noms com glúcids, lípids, colesterol, vitamines... Per què no donar-los unes etiquetes de llet, una cosa familiar, i que llegeixin la seva composició i a partir d'aquí podem parlar dels seus components? Per què no comparem la llet anglesa amb la catalana i així ja aprenem els noms del contingut en ambdues llengües?
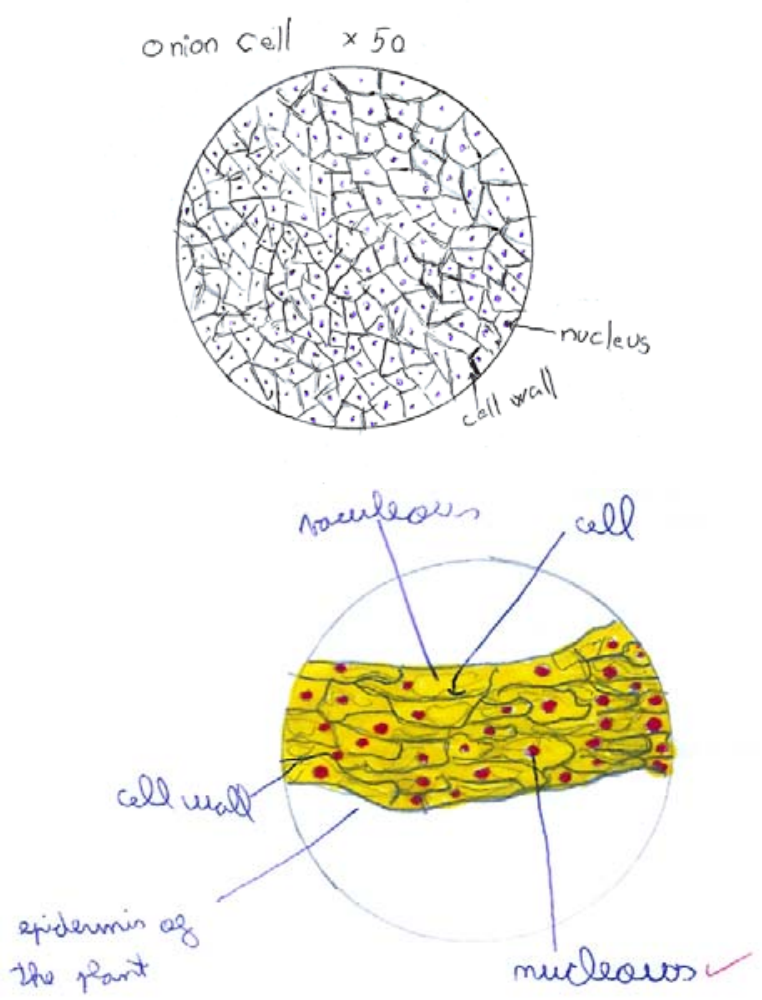

Figure 5. Students' drawings of onion cell.

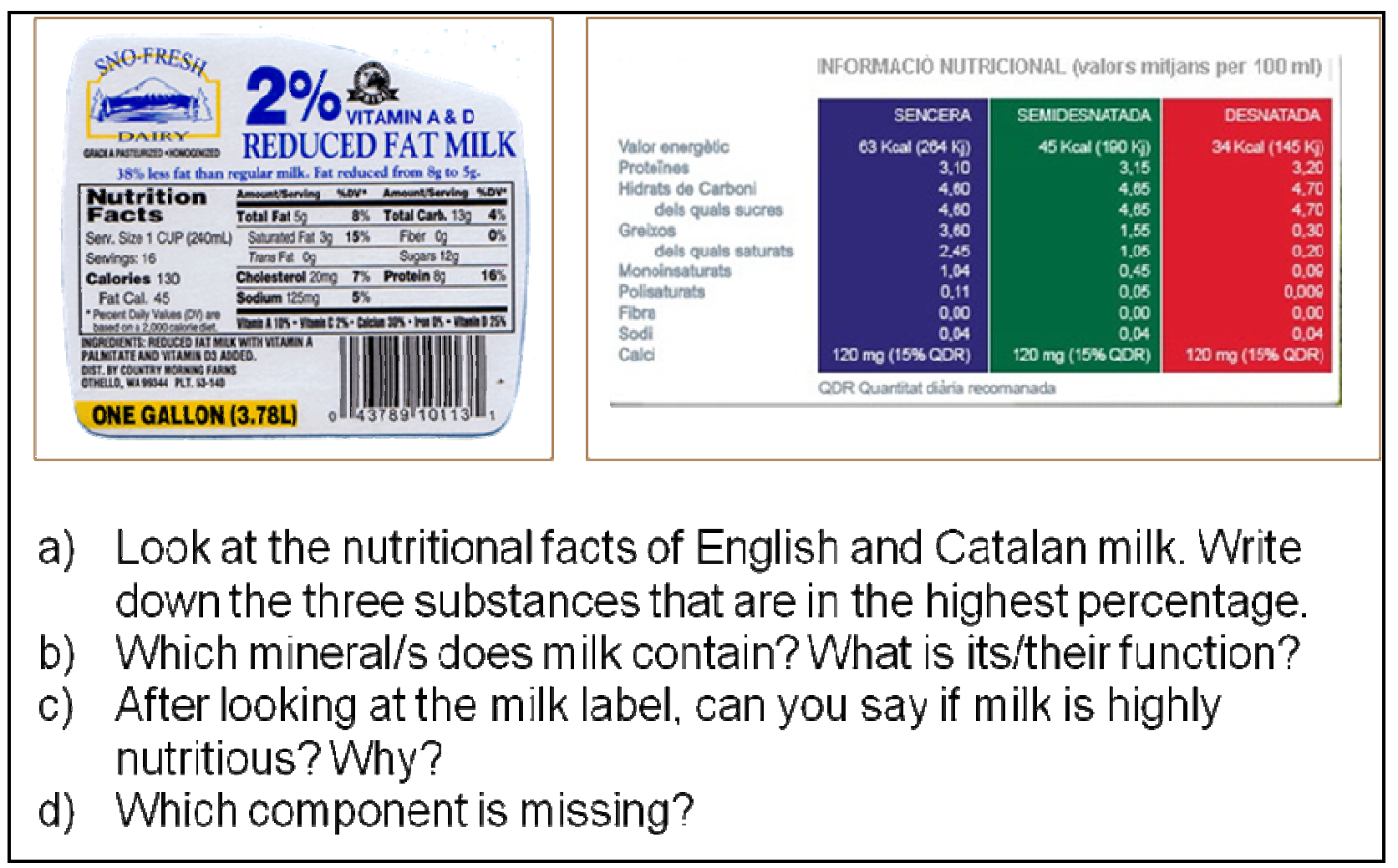

Figure 6. Activity which allows students connect real facts with abstract concepts. 


\section{Coordinació ciències - anglès}

Ens sembla fonamental una estreta coordinació entre el professorat de les dues matèries.

Hem de treballar amb vocabulari, però també amb gramàtica, hem d'aprendre a formular hipòtesis, dissenyar experiments, utilitzar connectors per relacionar, comparar, argumentar, raonar oralment $\mathrm{i}$ per escrit, etc. Per això hem d'adaptar les prioritats lingüístiques a les demandes científiques, i el professorat ha de treballar a la una. Els alumnes hauran d'aprendre a construir frases d'una manera gramaticalment correcta i amb els termes científics adients.

Aquí podem citar l'exemple d'una frase que ens podem trobar escrita o pronunciada pels alumnes: "Plants change to adapt to the environment". Aquí no hi ha errada gramatical, però podem pensar que hi ha implícita una idea lamarquiana d'evolució, per tant, ho hauríem de corregir per: "Plants are adapted to where they live", "If they are not adapted, they don't survive", per tal que quedi clara la idea darwiniana.

Som conscients que cada curs que avancin aniran fent millor aquestes frases que inicialment seran entenedores, però no sense errades.

\section{Valors}

Per acabar voldria comentar el que realment voldria aconseguir com a professora de ciències en anglès. Més que ciències i més que anglès, voldria que els alumnes fossin educats, conscients i responsables. Els nostres estudiants són els futurs ciutadans del món, per tant han de tenir opinions fonamentades i actituds respectuoses.

Per això, en les unitats didàctiques es lliga la matèria amb els valors.

En les tutories n'hem parlat molt i creiem que la nostra tasca només serà reeixida si els nostres alumnes, a banda d'aprendre ciències i anglès, arriben a fer front a les situacions mitjançant una actitud de respecte i responsabilitat.

\section{Conclusió}

Com a conclusió d'aquestes reflexions voldria assenyalar que en aquest procés d'ensenyar/ aprendre ciències en anglès he après a ensenyar d'una manera diferent.

M'he hagut de replantejar els coneixements científics i per a mi ( $\mathrm{i}$ els meus alumnes) ha estat molt útil. També he hagut de reconsiderar les metodologies tradicionals $i$, per tant, he intentat dissenyar activitats en les que els alumnes siguin molt actius en el procés de construir el seu coneixement.

Tot plegat ha estat i és molt enriquidor $i$ ho he pogut aplicar i ho aplico també a l'ensenyament de les ciències en català.

Espero que això pugui servir a altres professors: crec que la nostra feina pot ser tant o més creativa i interessant que moltes altres.

En el meu cas, ser un/a profesor/a AICLE consisteix en estar en un procés de repensar, reescriure i refer les tasques per tal d'aprendre a ensenyar ciències en anglès i també en català.

\section{Referències}

CENTRE FOR SCIENCE EDUCATION, Scheffield City Polytechnic (1992). Active teaching and learning approaches in Science. Collins Educational.

COYLE, D. (2005). Planning tools for teachers. University of Nottingham.

CUMMINS, J. (1984). Bilingualism and special Education: Issues in Assessment and Pedagogy. Clevedon: Multilingual Matters.

DELLER, S. AND PRICE, C. (2007). Teaching other subjects through English. Resource books for teachers. Oxford.

ESCOBAR URMENETA, C. (2004). Content and language integrated learning: Do they learn content? Do they learn language? In Anderson, J.D., Oro, J.M. and Varela, J. (eds), Linguistic Perspectives from the classroom: Language teaching in a multicultural Europe. Universidade de Santiago de Compostela: 27-38.

ESCOBAR URMENETA, C. (2008). Talking English to learn Science. A CLIL experience in Barcelona. In M. Dooly, ed., How we're going about it.' Teachers' voices on innovative approaches to teaching and learning languages. Cambridge: Cambridge Scholar Press. 154-169.

FRANCO, R. AND SANMARTÍ, N. (2003). Descriure: establir la manera de mirar els fets, In N. Santmartí, coord., Aprendre ciències tot aprenent a escriure ciencia. Barcelona: Edicions 62. 59-78.

HALLIWELL, S. (1992). Integrating language work in other subjects. In Halliwell, S. (ed.), Teaching English in the Primary Classroom. Harlow: Longman. 130-169.

LEMKE, J.L. (1990). Talking science: language, learning and values. Norwood, NJ: Ablex.

MARSH, D., MARSLAND, B. AND NIKULA, T. (eds.) (1997). Aspects of Implementing Plurilingual Education: seminar and field notes. Research and Field Reports 29. Jyväskylä: University of Jyväskylä. 
NAVÉS, T. AND MUÑOZ, C. (2000). Usar las lenguas para aprender y aprender a usar las lenguas extranjeras. Una introducción a AICLE para madres, padres y jóvenes. In Marsh, D. and Langé, G. (eds.), Using Languages to Learn and Learning to Use Languages. Jyväskylä. University of Jyväskylä - TIE-CLIL, 1-16.
SANMARTí, N. (2002). Didáctica de las ciencias en la educación secundaria obligatoria. Didáctica de las Ciencias Experimentales. Madrid: Síntesis Educación. 